\title{
Pharmaciana
}

Vol.9, No.2, Nov 2019, Page. 315-324

ISSN: 2088 4559; e-ISSN: 24770256

DOI: $10.12928 /$ pharmaciana.v9i2.13808

\section{Effect of sugar cane molasses and tofu waste on the inhibitory activity of cell free fermentation broth of streptomyces antibioticus $\mathrm{K}-6$}

\author{
Astrid Aulia Hamida, Noor Erma Nasution, Isnaeni* \\ Department of Pharmaceutical Chemistry, Faculty of Pharmacy Airlangga University \\ Gedung Nanizar Zaman Joenus, Universitas Airlangga Kampus C
}

Submitted: 05-08-2019

Reviewed: 20-09-2019

Accepted: 04-10-2019

\begin{abstract}
The use of waste as source of nutrition for human, animals, plants, and microorganism has been reported. The aim of this study was to observe the influence of sugar cane molasses (SCM) and tofu waste (TW) in various concentrations on the inhibitory effect of cell free fermentation broth (CFFB) of Streptomyces antibioticus K-6 isolated from plantation soil compare to International Streptomyces Project (ISP) standard media. The fermentation was performed in $150 \mathrm{rpm}$ rotary shaker at $37^{\circ} \mathrm{C}$ for five days. The inhibitory activity was investigated using diffusion agar on the nutrient agar media to determine ratio of SCM and TW by which the largest growth inhibitory zone achieved. Escherichia coli ATCC 25922 was used as a test microorganism. 10\% of Streptomyces antibioticus K-6 starter was inoculated into nine compositions of SCM, TW and its combination containing media. The result indicated that SCM and TWmight be used as the component of fermentation medium of Streptomyces antibioticus $K$ - 6 for producing active metabolites. The activity of CFFB was exhibited as a diameter of growth inhibitory zone against the test bacteria; in which the largest value $(24.4 \mathrm{~mm})$ was detected in the combination of $0.5 \% \mathrm{SCM}$ and $0.5 \% \mathrm{TW}$ containig medium after two days incubation.
\end{abstract}

Keywords: Molasses, tofu waste, Streptomyces antibioticus K-6, free cell fermentation broth

\footnotetext{
*Corresponding author:

Isnaeni

Department of Pharmaceutical Chemistry, Faculty of Pharmacy Airlangga University

Gedung Nanizar Zaman Joenus, Universitas Airlangga Kampus C

Email: isna.yudi@gmail.com
} 


\section{INTRODUCTION}

The incidence of resistance to antibiotics is increasing, with the development of various strains of microorganisms including Multi Drug Resistance (MDR), Methicillin Resistance Staphylococcus aureus (MRSA), and Extended Spectrum Beta Lactamase (ESBL) even MDR tuberculosis (TB). New antibiotics exploration, semi synthesis or total synthesis has been carried out, but has not been able to overcome the problems. Dependence on imported antibiotic raw materials is still a big problem. The genus of Actinomycetes known since 1943 has contributed a lot of antibiotics that have been clinical used. It was stated that two-thirds of natural antibiotics were isolated from Actinomycete (Solanki et al., 2008).

Isnaeni et al. (2015) hasisolated 15 Streptomyces sp. from plantation soil in Sidoarjo, East Java Indonesia.The isolates exhibited antibacterial activities, two of which were known as Streptomyces violaceous niger B-10 and Streptomyces antibiotics K-6. The two isolates were denoted invitro inhibitory activity against Mycobacterium tuberculosis H37Rv. The butanol extract of cell free fermentation broth (CFFB) of S. antibioticus K-6 has been proven to inhibit the growth of Staphylococcus aureus and Escherichia coli (Isnaeni et al., 2016).

The media used for both growth and fermentation of Streptomyces sp. is ISP-4. Previous studies have proventhat the tofu waste (TW) might be used as a component of antibacterial containing Streptomyces griseus fermentation media (Isnaeni, 2003). The high tofu production in Indonesia has an impact on the abundance of TW and not been utilized optimally (Anonymous, 2011). In 100 grams of TW contain raw protein and fat $22.3 \mathrm{~g}$ and $9.43 \mathrm{~g}$ respectively (Hernaman, 2005).

Molasses are byproducts derived from the manufacture of sugar cane (Saccharumofficinarum L.), in the form of thick liquid and obtained from the stage of separation of sugar crystals, containing $50-60 \%$ sugar consisting of $30-40 \%$ sucrose, $4-9 \%$ glucose, and 5-12\%fructose. In addition, the molasses also contain amino acids and minerals and is rich in biotin, pantothenic acid, thiamine, phosphorus, and sulfur (Hidayat et al., 2006). The molasses as a fermentation medium were used as a source of food ingredients for bacteria during the fermentation process. Bacteria will use carbohydrate as a source of food. When the source of carbohydrates in the medium has been used up, the bacteria switch to use a nitrogen source.

The ratio of carbon / nitrogen requirements for metabolism of secondary metabolites depends on the microbespecies and the metabolites produced, in addition to specific environmental conditions (Rafieene, 2016). Optimization of media type and concentration are very important to increase the productivity of metabolites produced by Streptomyces spp (Gao, 2009; Marques, 2011).This study evaluated prospective of SCM and TW as components of S.antibioticus K-6 fermentation media to produce metabolites that actively inhibit the growth of pathogenic microbes. The combination of SCM and TW containing media is expected to be further developed as an alternative medium for the production of antibiotics, especially from Streptomyces sp. The SCM was obtained from PT PG Rajawali I Surabaya, so that the specifications was accountable. The TW was obtained from the tofu industry in Sepande Village, Candi Sidoarjo East Java, as the qualified representative tofu industry.

\section{MATERIALS AND METHOD \\ Materials}

Sugar Cane Molasses and TW were obtained from PT PG Rajawali I, Surabaya and industryinSepande, Candi Sidoarjo, East Java. The Streptomycesantibioticus K-6 and Eschericia coli ATCC 25922 were available in the Laboratory of Microbiology, Faculty of Pharmacy, Airlangga University. Nutrient broth (Himedia), International Streptomyces Project/ ISP 4 (Difco), agar (Difco), distilled water, amylum (Himedia), Pharmaceutical grade of $(\mathrm{NH} 4)_{2} \mathrm{SO}_{4}, \mathrm{CaCo}_{3}, \mathrm{~K}_{2} \mathrm{HPO}_{4}$, $\mathrm{MgSO}_{4} \cdot 7 \mathrm{H}_{2} \mathrm{O}, \mathrm{NaCl}, \mathrm{FeSO}_{4} \cdot 7 \mathrm{H}_{2} \mathrm{O}, \mathrm{MnCl} \cdot 7 \mathrm{H}_{2} \mathrm{O}$, and $\mathrm{ZnSO}_{4} \cdot 7 \mathrm{H}_{2} \mathrm{O}$. 


\section{Characterization of sugar cane molasses and tofu waste}

Characterization of SCM was done included organoleptic, water, ash, reduction sugar, and total sugars content (SNI, 1989). While characterization of TW was performed included organoleptic, and then dried the TW using an oven at a temperature of $45^{\circ} \mathrm{C}$ to obtain $\pm 25 \%$ dry powder and then blended until a fine powder obtained.

\section{Preparation of Nutrient Agar media}

Weighed $8 \mathrm{~g}$ of nutrient brothand 18 gagarpowder to be dissolved in $1 \mathrm{~L}$ of distilled water and stirred until homogeneous liquid obtained. The solution was heated while stirring so that all components were dissolved. The nutrient solution was subsequently sterilized by autoclaving at $121^{\circ} \mathrm{C}$ for 15 minutes. The solution was poured into a sterile petri dish and left to cool and solidify, and then closed and stored in the refrigerator until used (Isnaeni et al., 2015).

\section{Preparation of ISP-4 media}

Weighed $37 \mathrm{~g}$ ISP-4 powder Medium was mixed in 1L purified water and stirred to obtainhomogenous solution. Boiling the solution was performed for 1 minute so that the powder was evenly. The ISP-4 media was sterilized by autoclaving at $121^{\circ} \mathrm{C}$ for 15 minutes. The suspensionwas poured into a petri dish with constant agitation to get a homogeneous suspension (Isnaeni et al., 2015).

\section{Preparation of SCM and TW media}

The Molasses and dried TW were prepared in various composition, divided into formula A (0.5\% SCM), B (1.0\% SCM), C (2.0\% SCM), D $(0.5 \% \mathrm{TW}), \mathrm{E}(1.0 \% \mathrm{TW}), \mathrm{F}(2.0 \% \mathrm{TW})$. Formula G

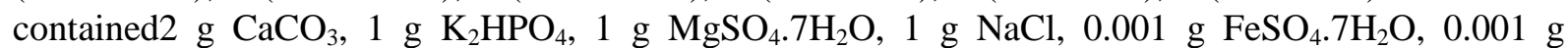
$\mathrm{MnCl} .7 \mathrm{H}_{2} \mathrm{O}$ g, $0.001 \mathrm{~g} \mathrm{ZnSO} \cdot 7 \mathrm{H}_{2} \mathrm{O}$ dissolved with $1 \mathrm{~L}$ sterile distilled water, stirred until homogeneous, then the solution was sterilized by autoclaving at $121^{\circ} \mathrm{C}$ for 15 minutes. The solution was poured into sterile Erlenmeyerflask by agitation to form a homogeneous suspension (Isnaeni, 2003).

\section{Fermentation process}

The $10 \mathrm{ml}$ of starter was inoculatedin $100 \mathrm{~mL}$ of ISP-4 liquid media, SCM and TW containing media in various compositions in Erlenmeyer flasks. Incubation was performed using a thermo shaker $150 \mathrm{rpm}$ at $26-28^{\circ} \mathrm{Cfor} 5$ days. The fermentation broth was then homogenized and the optical density was measured.Thecell free fermentation broth (CFFB) was obtained from supernatant after the fermentation broth was centrifuged. Furthermore, the inhibitory activity of CFFB against the test bacteria was observed (Isnaeni, 2003).

\section{Preparation of bacterial inoculum}

One Öse of the test bacterium was inoculated on the nutrient slant agar medium and then incubated at $37^{\circ} \mathrm{C}$ for 24 hours. The $5 \mathrm{ml}$ of saline solution was added to the tube and shaken until the colony on the entire surface was released. The density of the inoculum was measured by a spectrophotometer with a wavelength of $580 \mathrm{~nm}$ to obtain $25 \%$ transmittance, dilution with a saline solution was performed if necessary (Isnaeni et al., 2016).

\section{Inhibitory activity test}

The $10 \mathrm{ml}$ of melted Nutrient agar $\left(40-50^{\circ} \mathrm{C}\right)$ media as the base layer was poured into a petri dish, awaited until solidified. The $8 \mathrm{~mL}$ of melted Nutrient agar $\left(40-50^{\circ} \mathrm{C}\right)$ media was inoculated by $3 \mu \mathrm{L}$ test bacterial inoculum with transmittance value of $25 \%$ at a wavelength of $580 \mathrm{~nm}$, vortex until homogeneous and then poured over the base layer and wait until solidified. The test media was perforated to make a hole. The $80 \mu \mathrm{L}$ of sample was taken with a micropipette and inserted into the prepared hole. As a positive control, agar nutrient media was inoculated with the test bacteria. After 
incubation at $37^{\circ} \mathrm{C}$ for 24 hours,the clear zone inhibition observed and growth curve wasmade compared to the growth profile in all media. Test of growth inhibitory activity against Escherichia coli ATCC 25922 was performed to determine optimal SCM and TW concentrations that produce the highest inhibitory activity. Observation of antibacterial activity was carried out by measuring the diameter of the inhibition zone (mm) (Isnaeni et al., 2016; Balouiri et al., 2016).

\section{RESULTS AND DISCUSSION}

\section{Characteristic of SCM and Tofu Waste}

The characteristics of SCM were in accordance with SNI 01-1679-1989 for SCM A quality, blackish brown liquid, sweet taste, typical smell with $18.13 \%$ moisture content (SNI: 15-21\%), total sugar content $66.3 \%$ (SNI: 60\%), $10.33 \%$ ash content (SNI does not specify). The characterization of wet TW was like a slurry and the dried powder was in the form of granules, white, salty, distinctive smell of tofu.

\section{Growth rate of Streptomyces antibioticus K-6}

Production of S. antibioticus K-6 biomass was measured as optical density, observed every 24 hours for five days of the fermentation in seven composition of media (Table I). The peak of growth was achieved on the $3^{\text {rd }}, 4^{\text {th }}, 4^{\text {th }}, 3^{\text {rd }}, 4^{\text {th }}, 5^{\text {th }}$, and $3^{\text {rd }}$ days for SCM $0.5 \%, 1 \%, 2 \%$ and TW $0.5 \%, 1 \%$ and $2 \%$, and ISP-4containing mediarespectively (Figure 1 and Figure 2).Data analysis was performed using Statistical product and Service Solution (SPSS) with a variance analysis (ANOVA) two way design and continued by the Tukey test at a confidence level of $95 \%$ or a significant level of $\alpha=0.05$. If the calculation based on probability values, there was no significant difference between the treatment groups, if the probability $>0.05$. On the other hands, stated on the contrary if the probability is $<0.05$ then there was a significant difference between the treatment groups (Landau and Everitt, 2004).

Metabolite production during the fermentation process was influenced by the components and concentration of fermentation media. Various factors can influence the metabolism of antibiotics produced by Streptomycetes, including sources of carbon, nitrogen phosphate and tracer elements (Rafieenia, 2013). The source of carbon mainly acts as a regulator in the production of secondary metabolites in Streptomyces sp. (Ruiz et al., 2010).

Carbon source usually constitute the major part of a culture media, therefore it has been the subject of many studies on optimization antibiotic production. Different sugars and proteins in SCM and TW will produce different speeds of growth and biomass results, due to the availability of different carbon and nitrogen sources.

Tablel I. Optical density of fermentation broth of S.antibioticus K-6

\begin{tabular}{|c|c|c|c|c|c|c|c|}
\hline \multirow{2}{*}{ Day } & \multicolumn{7}{|c|}{ Average of optical density on thesevenformula of fermentation media } \\
\hline & Media A & Media B & Media C & Media D & Media E & Media F & ISP-4 \\
\hline \multirow{2}{*}{1} & $0.413 \pm$ & $1.033 \pm$ & $1.313 \pm$ & $0.510 \pm$ & $0.777 \pm$ & $0.459 \pm$ & $0.883 \pm$ \\
\hline & 0.010 & 0.153 & 0.040 & 0.003 & 0.000 & 0.012 & 0.039 \\
\hline \multirow{2}{*}{2} & $0.606 \pm$ & $1.232 \pm$ & $1.850 \pm$ & $0.342 \pm$ & $0.762 \pm$ & $0.562 \pm$ & $1.328 \pm$ \\
\hline & 0.000 & 0.052 & 0.051 & 0.025 & 0.019 & 0.055 & 0.002 \\
\hline \multirow{2}{*}{3} & $0.495 \pm$ & $1.393 \pm$ & $1.902 \pm$ & $0.475 \pm$ & $1.073 \pm$ & $0.760 \pm$ & $1.914 \pm$ \\
\hline & 0.060 & 0.129 & 0.016 & 0.047 & 0.095 & 0.013 & 0.052 \\
\hline \multirow{2}{*}{4} & $0.707 \pm$ & $1.179 \pm$ & $1.866 \pm$ & $0.739 \pm$ & $0.625 \pm$ & $0.914 \pm$ & $1.575 \pm$ \\
\hline & 0.148 & 0.026 & 0.023 & 0.093 & 0.044 & 0.055 & 0.006 \\
\hline \multirow{4}{*}{5} & $0.683 \pm$ & $1.304 \pm$ & $2.090 \pm$ & $0.592 \pm$ & $0.791 \pm$ & $1.052 \pm$ & $1.669 \pm$ \\
\hline & 0.124 & 0.178 & 0.008 & 0.150 & 0.035 & 0.022 & 0.034 \\
\hline & & M $0.5 \%$ & Media C & CM 2\% & & & vaste $1 \%$ \\
\hline & Media B : & M $1 \%$ & Media D & ofu waste & & dia F: Tofu & vaste $2 \%$ \\
\hline
\end{tabular}


Using sole carbon source like glucose and other carbohydrates have an adverse effect on antibiotic synthesis (Sanchez et al., 2010). It has been reported that glucose decreases production of avilamycin (Zhu et al., 2007), nystatin (Jonsbu et al., 2002), and Neomycin (Vastrad et al., 2010). The Streptomyces has been found in different environments, which frequently turn out to be complex, therefore, for growth developing purposes, they must compete with other microorganisms for the nutrients present in the environment. Usually, they have the ability to produce a wide range of secondary metabolites, such as antibacterial substances (Xiong et al., 2004).

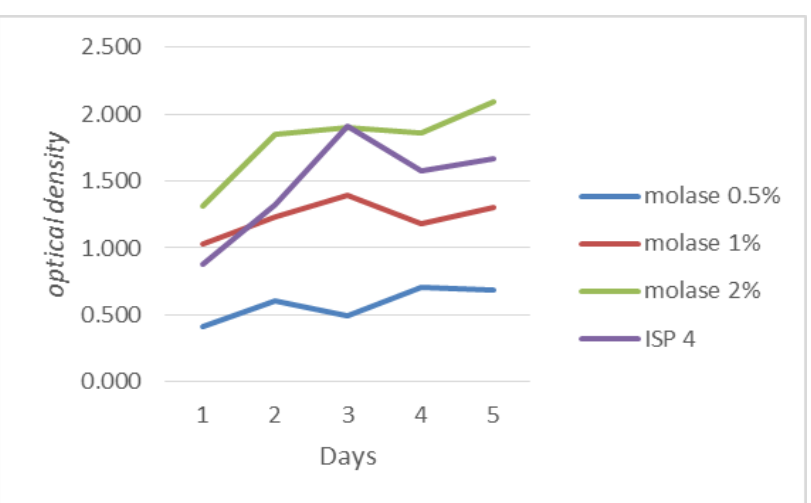

\section{Figure 1. Streptomycesantibioticus K-6 growth curve on the SCM (molase) and ISP-4 media}

In addition, nutrients in nature are usually present in a wide range of complexity, such as SCM and TW, so microorganisms must have the necessary tools to succeed in their utilization. For achiving this purpose, 819 potentially secreted proteins have been predicted to operate in Streptomyces coelicolor. Among them, amylases, cellulases/ endoglucanases, chitinases/chitosanases, proteases/peptidases, and pectate lyases are of special importance and many of these enzymes also have commercial interest (Bentley et al., 2002). Furthermore, due to their capability to degrade multiple natural polymers, the Streptomycetes play an important role in soil ecology Streptomyces spp. dominate the land as their habitat, with antibiotic metabolite products some of which have been used clinically.

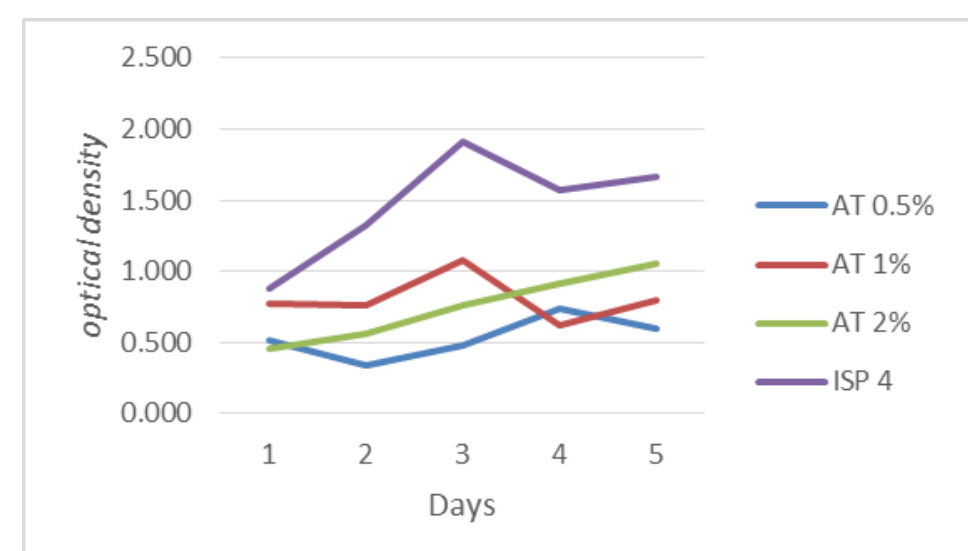

Figure 2. Streptomyces antibioticusK-6 growth curve on TW (AT)and ISP-4 media

Based on the results of growth optimization, fermentation is carried out to produce active metabolites in media containing $\operatorname{SCM}(\mathrm{A}, \mathrm{B}, \mathrm{C})$, TW (D, E, F) and their combinations with a composition of $0.5 \%$ : $0.5 \%(\mathrm{G}), 1 \%: 1 \%(\mathrm{H})$, and $2 \%: 0.5 \%(\mathrm{I})$. 


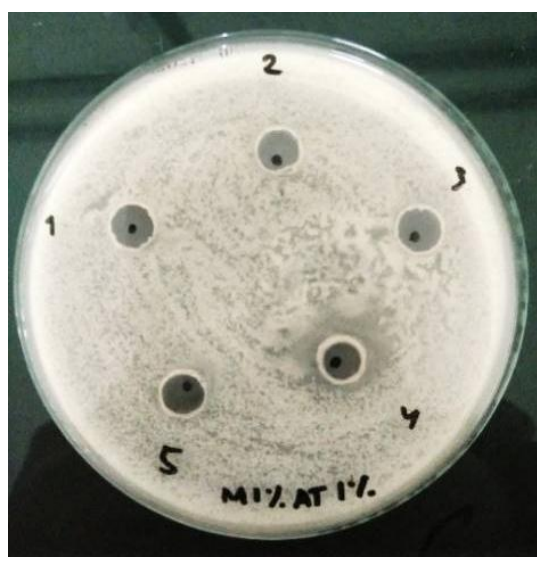

G

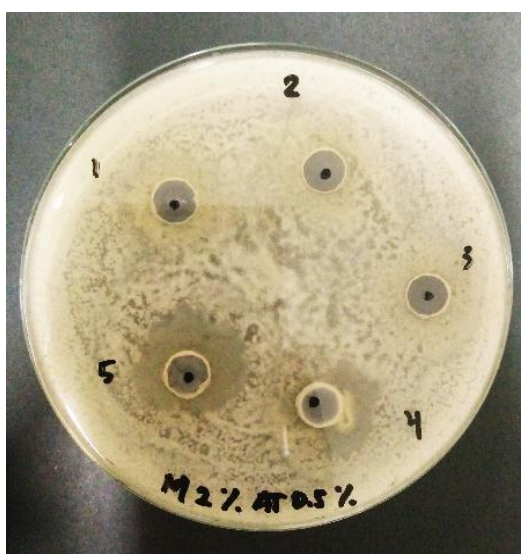

$\mathbf{H}$

Figure 3. Inhibitory activity of S. antibioticus K-6 CFFB on the SCM 1\% and TW 1\% (G), SCM $2 \%$ and TW $0.5 \%$ (H) containingmedia after 1 day, 2, 3, 4, and 5 days incubation

The production of metabolites was exhibited as the diameter of the inhibitory zone $(\mathrm{mm})$ around the reservoir in holes $6 \mathrm{~mm}$ in diameter (Figure 3) showed the highest inhibitory activity against the test bacterial in the media G (Figure 4).

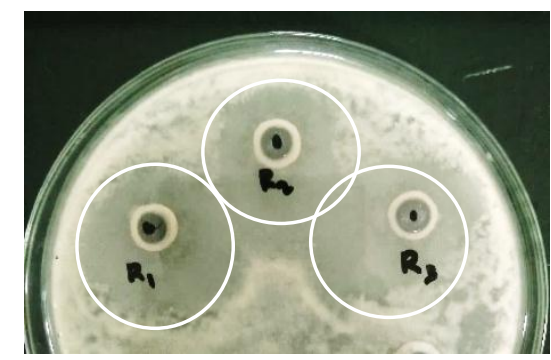

Figure 4. Inhibitory activity of cell free fermentation broth of $S$. antibioticus K-6 on the media containing SCM $0.5 \%$ and TW $0.5 \%$ (I) after 2 days fermentation

The measurement results of inhibitory zone diameter indicated the potency of the metabolites produced in CFFB of S. antibioticus K-6 against Escherichia coli ATCC 25922, showing the work of extra cellular enzymes. The largest antibacterial activity obtained with the ISP-4 media was reached on the fourth day with an average diameter of the inhibition zone of $20.2 \mathrm{~mm}$. In the combination of $0.5 \% \mathrm{SCM}$ and $0.5 \% \mathrm{TW}$ containingmedia, the highest activity was obtained on the second day of fermentation with an average inhibition zone diameter of $24.4 \mathrm{~mm}$ (Figure 4), greater than the activity on the ISP-4 media. The largest activities with media $\mathrm{H}$ and I were achieved on the fourth and fifth days with inhibition zone diameters of $15.8 \mathrm{~mm}$ and 19.9 mmrespectively.

The A-C media with higher SCM content resulted lower antibacterial activity with longer production times, whilemedia $\mathrm{D}$ did not show antibacterial activity at all. It was found the antibacterial activity in the E media was starting from the third day of fermentation with the greatest activity on the fourth day, whereas in $\mathrm{F}$ medium the greatest antibacterial activity was achieved on the first day.

Previousstudies have proved that nature and concentration of nitrogen sources in culture of strptomycetes sp. affected antibiotic synthesis strongly. Quickly metabolize of nitrogen sources, usually decrease antibiotic production in different microorganisms as well as streptomycetes. Different studies have shown that complex nitrogen sources such as soybean meal, corn steep liquor 
and yeast extract have increased the production of antibiotics by Streptomycetes which could be attributed to slow decomposition of these compounds in the medium (Gao et al., 2009; Marquez et al., 2011). It seems using inorganic nitrogen sources lead to high ammonium concentrations in culture medium and suppress antibiotic production in many microorganisms. Therefore, medium containing ammonium saltsas the sole nitrogen sources are not suitable for antibiotic production and supplement edwith high concentrations of complex nitrogen sources in antibiotic production industries. Unfortunately, the leak in the use of complex media derived from nature because of it is difficult to standardize.

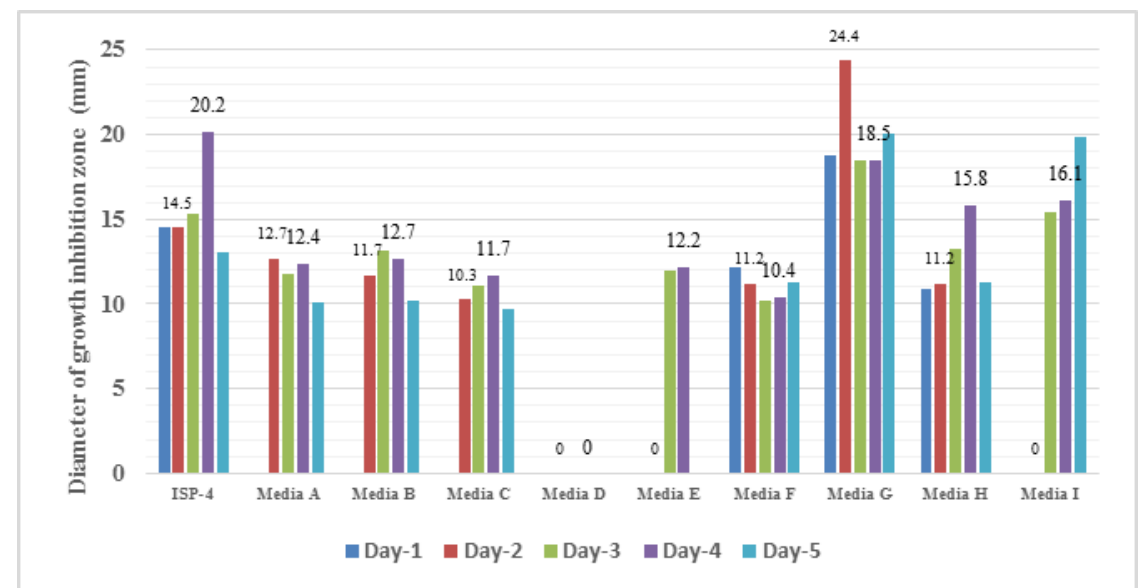

Figure 5. Inhibitory activity of cell free fermentation broth of $S$. antibioticus K-6 on the media containing 0.5\% SCM (A), 1\% (B), 2\% SCM (C), 0.5\% (TW), 1\% TW (D), 1\% (E), $2 \%$ TW (F), 1\% SCM + 1\% TW (G), 2\% SCM + 0.5\% TW(H), 0.5\% SCM + 0.5\% TW (I) after one day, two, three,four, and 5 days fermentation

Significant differences in ISP-4 with media D were identified in the media (TW 0.5\%), but not with media A (0.5\% SCM). Media D did not respond to resistance to the test bacteria. This phenomenon shows that the role of carbon sources is more important than nitrogen in synthesizing secondary metabolites from $S$. antibioticus K-6 compared to ISP-4 which contain more complete nutrients, derived from different sources. The carbon source from TW is not enough to provide carbon for the metabolism of active compounds. Therefore, when the TW combined with SCM at a concentration of $0.5 \%$ each, the resulting resistance activity was greater than ISP-4 on day 2. Even though the diameter of the inhibitory zone did not differ in meaning, the onset of action in media $G$ was faster than ISP-4. Nitrogen sources that are easily degraded usually reduce metabolite production, meanwhile different studies have proved that complex nitrogen sources such as soybean meal, corn steep liquor and yeast extract can increase the production of antibiotics produced by Streptomycetes which can be attributed to slow decomposition of these compounds in the medium (Gao et al., 2009; Abdelghani, 2011). It seems using inorganic nitrogen sources which lead to high ammonium concentrations in culture medium lead to suppress antibiotic production in many microorganisms. As a result of this, medium containing ammonium salts as the sole nitrogen sources are not suitable for antibiotic production and supplemented with high concentrations of complex nitrogen sources in antibiotic production industries.

\section{CONCLUSION}

The combination of sugar cane molasses and tofu waste might be considered as a component of Streptomyces antibioticus K-6 fermentation media to produce antibacterial metabolites against Escherichia coli ATCC 25922. The fermentation media containing 0.5\% sugar cane molasses and $0.5 \%$ tofu waste obtained the greatest inhibitory activity against Escherichia coli ATCC 22259 
growth with inhibitory zone diameter values 1.7 times compared to ISP-4 as fermentation standard media.

\section{ACKNOWLEDGEMENT}

The authors are grateful to the Assessment Service Unit Faculty of Pharmacy Airlangga University for contribution in the characterization of Sugar Cane Molasses and Tofu Waste.

\section{REFERENCES}

Abdelghani,T., 2011, Production of antibacterial metabolites by strain no.10/2 (S. albovinaceus) and media optimization studies for the maximum metabolite production. IJPI.J. Biotech.,1(5): 1-11.

Anonymous. Dinas Peternakan Propinsi Jawa Timur., 2011, Pemanfaatan ampas tahu sebagai pakan ternak. http://disnak.jatimprov.go.id/web/layananpublik/readtehnologi/811/pemanfaatan--astahu-sebagai-pakan-unggas. Diakses 27 Juli 2019.

Balouiri, M., Sadiki M, Ibnsouda SK., 2016, Methods forin vitro evaluating antimicrobial activity: A review. Journal of Pharmaceutical Analysis. 6: 71-79.

Bentley, S.D., Chater, K.F., Cerdeño-Tárraga, A.M., Challis, G.L., Thomson, N.R., James, K.D., et al., 2002, Complete genome sequence of the model actinomycete Streptomyces coelicolor A3 (2). Nature 417:141-147.

Gao,H.,Liu,M.,LiuJ.,Dai,H.,Zhou,X.,Liu,X.,Zhou,Y., Zhang,W., Zhang, L., 2009, Medium optimization for the production of avermectin B1a by Streptomyces avermitilis. Technol.,100(17):4012-4016.

Hernaman, I., Hidayat, R., Mansyur., 2005, Effect of using molasses in mix silage processing of tofu waste and dry top cane on $\mathrm{pH}$ value and nutrient composition. Jurnal Ilmu Ternak, 5(2): 9499.

Hidayat, N., Padaga, M.C., Suhartini, S,. 2006, Mikrobiologi Industri. Andi Offset, Yogyakarta.

Isnaeni. 2003. Optimization of environmental and nutrition factors for antibiotics fermentation of Streptomyces $s p$. by using tofu refuse as a one of nutrient component Research Grant of QUE Project, Faculty of Pharmacy Airlangga University. Surabaya.

Isnaeni, Mega, F.W., Noor, E.N., Ni Made, M., Achmad, T.P., Dina, F., Astri, A.H., Hanifah. 2015, Antibacterial activity of butanol extract from cell free fermentation broth of Streptomyces spp. isolated from vegetable plantation soil. Research Journal of Pharmaceutical, Biological and Chemical Sciences, 8(1): 1056-1060.

Isnaeni,Idha,K., Mega, F.S., Asri,D., Ni Made, M., 2016, Antimicrobial activity of streptomyces spp. isolates from vegetable plantation soil. Journal of Biological Researches, 21(2): 10-13.

Jonsbu,E.Mc.Intyre,M.,Neilson, J., 2002. Theinfluenceofcarbon sources and morphology on nystatin production by Streptomycesnoursei Journal of Biotechnology, 95(2):133-144.

Landau, S., and Everitt, BS., 2004, A Handbook of statistical analyses using SPSS. Chapman \& Hall/CRC. ACRC Press Company: 38-62.

Marques,D.A.V., Cunha,M.N.C.,Araujo,J.M.,Filho,J.L.,Converti, A.,Pessoa-Jr, A.,Porto, A.L.F., 2011, Optimization on clavulanic acid production by Streptomyces DAUFPE3060 by response surface methodology. Brazilian Journal of Microbiology, :42(2):658-667.

Rafieenia, R., 2013, Effect of nutrients and culture conditions on antibiotic synthesis in Streptomycetes. Asian Journal of Pharmaceutical and Health Sciences, 3(3): 810-815.

Ruiz, B., Adán, C., Angela, F., Yolanda, G.H., Alba, R., Mauricio, S., Diana, R., Brenda, S., Romina, R.S., Sergio, S., Elizabeth, L., 2010, Production of microbial secondary metabolites: Regulation by the carbon source. Critical Reviews in Microbiology, 36(2): 146-167.

Sanchez,S., Chavez,A., Forero, A., Garcia-Hunte,Y, Romero,A., Sanchez,M., Rocha,D., Sanchez,B., AvalosM, Guzman-Trampe S, Rodriguez-Sanoja R, Langley E, RuizB.2010. Carbon source regulation of antibiotic production, The Journal of Antibiotics, 63(8):442-459. 
SNI. Standar Nasional Indonesia 01-1679-1989. 1989. Tetes. https://fdokumen.com/download/sni-011679-1989-tetes-tebupdf. (Access on 05 August 2019).

Solanki,R., Khanna,M., Lal, R., 2008, Bioactive compounds from marine actinomycetes. Indian journal of microbiology, 48(4): 410-431.

Vastrad, B.M., Nelagund, S.E., 2011, Optimization and production of neomycin from different agro industrial wates in solid state fermentation, International Journalof Pharmaceutical Sciences and Drug Research. 3(2):104-111.

Xiong, L., Li, J., Kong, F., 2004, Streptomyces sp 173, an insecticidal micro-organism from marine. Lett Appl Microbiol, 38: 32-37.

Zhu,C.H.,Lu,F.P,He,YN.,Han,Z.L.,DuL,X., 2007, Regulation of avilamycin biosynthesis in Streptomyces viridochromogenes: effect of glucose, ammonium ion and inorganic phosphate. Appl. Microbiol. Biotechnol, 73(5):1031-1038. 
